\title{
Relationship between NDVI, LAI, fIPAR in wheat Under Reduced Solar Radiation in Delhi NCR Region
}

\author{
Brijesh Yadav $^{1 *}$, Anil Kumar Verma ${ }^{2}$, Sushil Kumar Kharia ${ }^{1}$, Avinash Goyal, \\ Ravi Kumar Meena ${ }^{2}$ and Chiranjeev Kumawat ${ }^{2}$
}

${ }^{1}$ Divison of Agricultural Physics, ${ }^{2}$ Division of Soil Science and Agricultural Chemistry, ICARIndian Agricultural Research Institute, New Delhi 110012, India

*Corresponding author

\section{A B S T R A C T}

\section{Keywords}

Wheat,

Shading,

Soil moisture,

Spectral

radiance,

NDVI.

Article Info

Accepted:

25 April 2017

Available Online:

10 May 2017
A field experiment was carried out at the farm of ICAR-Indian Agricultural Research Institute, New Delhi during rabi season of 2014-15 and 2015-16. The study was conducted to observe response of wheat under reduced solar radiation. In this experiment, three wheat cultivars namely, HD 2967, WR 544 and PBW 502 were grown under five solar radiation reduction treatments i.e. R1 (control), R2 (20\% shading), R3 (35\% shading), R4 (50\% shading) and R5 (75\% shading) levels. Ground held spectroradiometer was used for spectral reflectnance measurement of wheat canopy. Finally normalized difference vegetation index (NDVI) was calculated for different treatments. The different regression equations between LAI -NDVI and fIPAR-NDVI were developed for different treatments for both years. The positive correlations were observed for all treatments during both years. Spectral radiance of blue band $(400-500 \mathrm{~nm})$ was more inside the severe shading compared to mild shading and control. But spectral radiance of red band $(620-700 \mathrm{~nm})$ was less inside the severe reduced radiation treatments in both the seasons.

\section{Introduction}

Solar radiation is the ultimate energy source for plants to regulate the growth and development. Solar radiation reaches the Earth's surface either as direct ray without scattering from the Sun or in diffuse form after scattering through atmospheric constituents. The sum total of the direct and diffuse radiations reaches the Earth's surface is known as global radiation. As a consequence of increase in aerosol content, black carbon and air pollutants, light dimming or reduction in global solar radiation have become a major challenge for crop production in many areas of the world. Long-term observations confirmed that global solar radiation has a widespread declining trend in many parts of the world (Liepert, 2002 and Liu et al., 2004). India also shows a steady light dimming condition since 1960s (Wild et al., 2005 and Ramanathan et al., 2005). Many researchers have been observed that mean annual diffuse radiation is $92.6 \mathrm{Wm}-2$, with a mean standard deviation of 4.7 Wm-2 through whole Delhi (Soni et al., 2012). India 
also shows a decreasing trend of solar radiation with $-0.86 \mathrm{~W} / \mathrm{m} 2$ since 1981 (Kumari et al., 2007). Aerosol, significantly affect, the plant growth and development through changing the upcoming photosynthetically active radiation (PAR, 400-700 nm) as well as short wave radiation. Atmospheric aerosol content, air pollutant and black carbon have been able to scatter and absorb the incoming solar radiation and ultimately increase the diffuse fraction (Greenwald et al., 2006).

Diffuse light has a higher blue: red light ratio which may enhance photochemical reactions and stomata activity (Urban et al., 2012). It also modifies the quality of light spectrum (Bell et al., 2000). Li et al., (2010) suggested that with increasing shading intensity, blue light $(400-500 \mathrm{~nm})$ fraction increases but red light $(600-700 \mathrm{~nm})$ decreases. Keeping in view the importance of radiation dimming present study was conducted to study the growth pattern of wheat crop under reduced solar radiation.

\section{Materials and Methods}

\section{Site characterization}

The experiment was carried out at research farm of Indian Agricultural Research Institute (IARI), New Delhi (28 $37^{\prime} \mathrm{N}$ latitude, $77^{\circ} 09^{\prime}$ E longitude). The soil of experiment site was sandy loam having $\mathrm{pH}$ 7.3, organic carbon 0.47 percent, available nitrogen $170.6 \mathrm{~kg} \mathrm{ha}^{-1}$, and available phosphorus $18.6 \mathrm{~kg} \mathrm{ha}^{-1}$ and available potassium $275.0 \mathrm{~kg} \mathrm{ha}^{-1}$.

\section{Experimental details}

In this experiment, three wheat cultivars (HD 2967, WR 544 and PBW 502)were grown under five solar radiation treatments i.e. R1 (no shading), R2 (20\% shading), R3 (35\% shading), R4 (50\% shading) and R5 (75\% shading) during rabi season of 2014-15 and
2015-16. In this experiment split plot design was followed with three replications in $5 \mathrm{~m} \times$ 3 m plots. A dose of 120:60:60 kg ha ${ }^{-1}$ of N: P: $\mathrm{K}$ was applied (three split dose of $\mathrm{N}$ as basal, $\mathrm{CRI}$ and flowering).

\section{Spectral distribution of insolation}

Ground held spectroradiometer was used for spectral reflectance measurement of wheat canopy in the field. The spectral data were processed and exported by ASD View Spec Pro software to MS excel. Finally normalized difference vegetation index (NDVI) was calculated by using equation given by Rouse et al., (1974).

$\mathrm{NDVI}=(\mathrm{NIR}-\mathrm{R}) /(\mathrm{NIR}+\mathrm{R})$

Where, NIR- Near infrared band (841-876 nm)

$\mathrm{R}$ - Red band (620-670 nm)

\section{Leaf Area Index measurement}

LAI were measured weekly by using LAI2000 Plant Canopy Analyzer (LI-COR, USA).LAI readings was measured in each plot and then averaged them for each plot.

\section{Photo synthetically Active Radiation (PAR)}

The incoming photo-synthetically active radiation (PAR) was measured from plant canopy and reflected from soil by using line quantum sensor (LICOR- 3000, U.S.A.). Different fractions of photosynthetically active radiation (PAR) like intercepted photosynthetically active radiation (IPAR), fraction IPAR (fIPAR) and absorbed PAR (APAR) were calculated by using following formulas:

IPAR $=$ I0 - It

APAR $=(\mathrm{I} 0+\mathrm{Ie})-(\mathrm{Ir}+\mathrm{It})$

fIPAR $=($ IO-It $) /$ I0

Where,

$\mathrm{I} 0=$ Incident PAR at the top of the canopy

It $=$ Transmitted PAR at the bottom of the canopy 
Ir $=$ Reflected energy flux from plant canopy

$\mathrm{Ie}=$ Reflected energy flux from soil surface

\section{Results and Discussion}

\section{Spectral radiance}

The spectral radiance of wheat varieties were influenced by the degree of reduced radiation during 2014-15 and 2015-16. More spectral radiance was received by $\mathrm{R} 1$ treatment followed by R2, R3, R4 and R5 respectively (Fig 1). A sharp reduction was observed in $759 \mathrm{~nm}$ band in rabi 2014-15 and $760 \mathrm{~nm}$ in rabi2015-16. Spectral radiance of blue band (400-500nm) was more inside the severe nets compared to mild net and open condition. But spectral radiance of red band $(620-700 \mathrm{~nm})$ was less inside the severe reduced radiation treatments in both the seasons.

Fig.1 Effect of reduced solar radiation on spectral radiance in wheat crop during rabbi season (A) 2014-15 (73 DAS) and (B) 2015-16 (78 DAS)
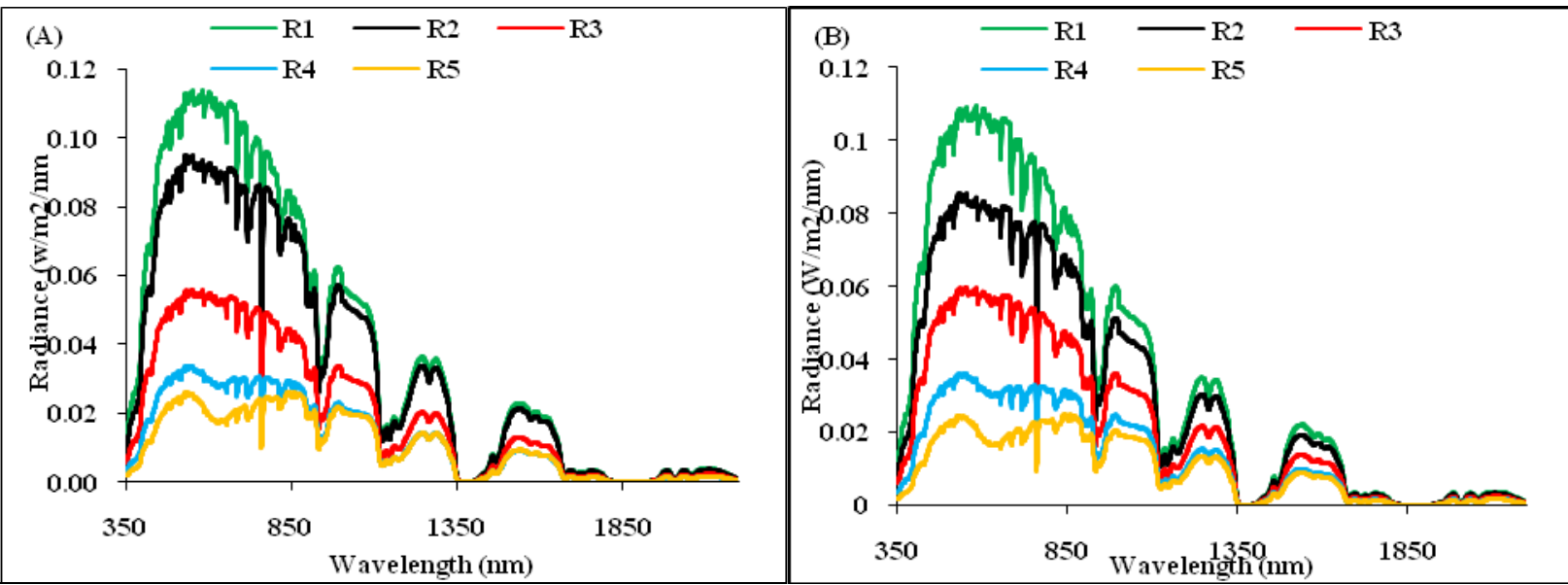

Fig.2 Effect of reduced solar radiation on percent reduction in different wavelength in wheat crop during rabi season (A) 2014-15 (73 DAS) and (B) 2015-16 (78 DAS)

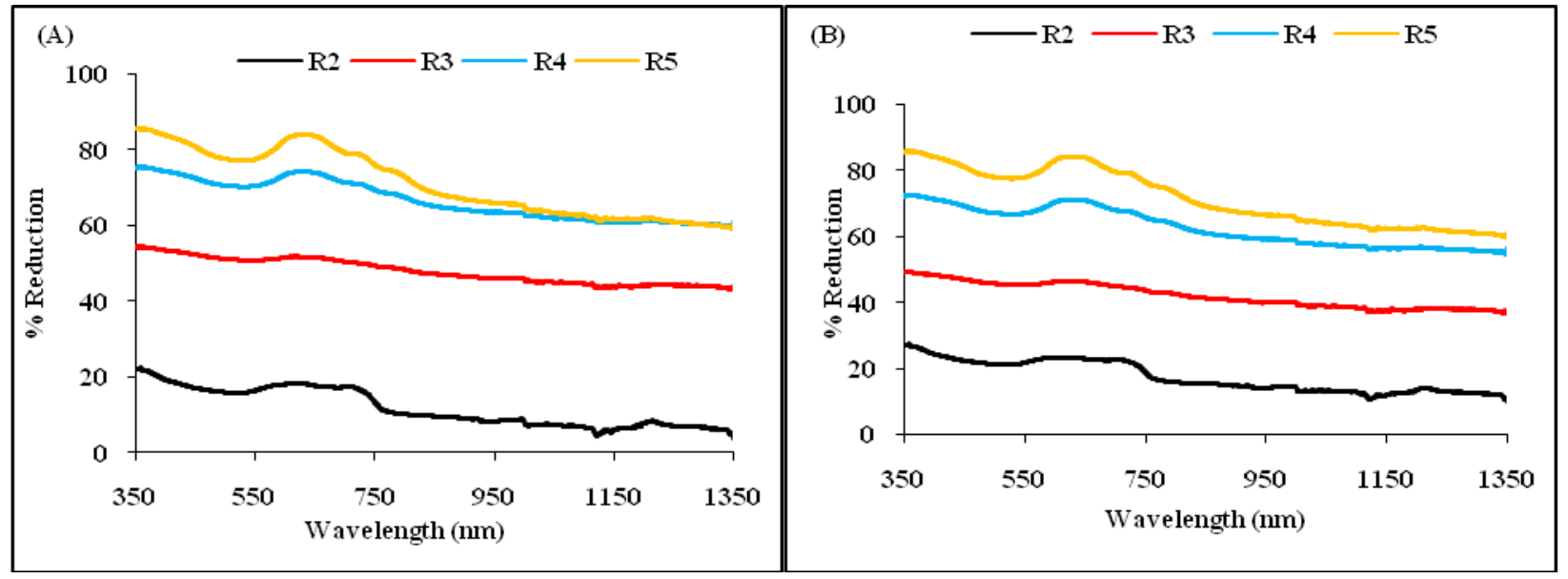


Fig.3 Relationship between NDVI and LAI (A) 2014-15(B) 2015-16 at 78 DAS

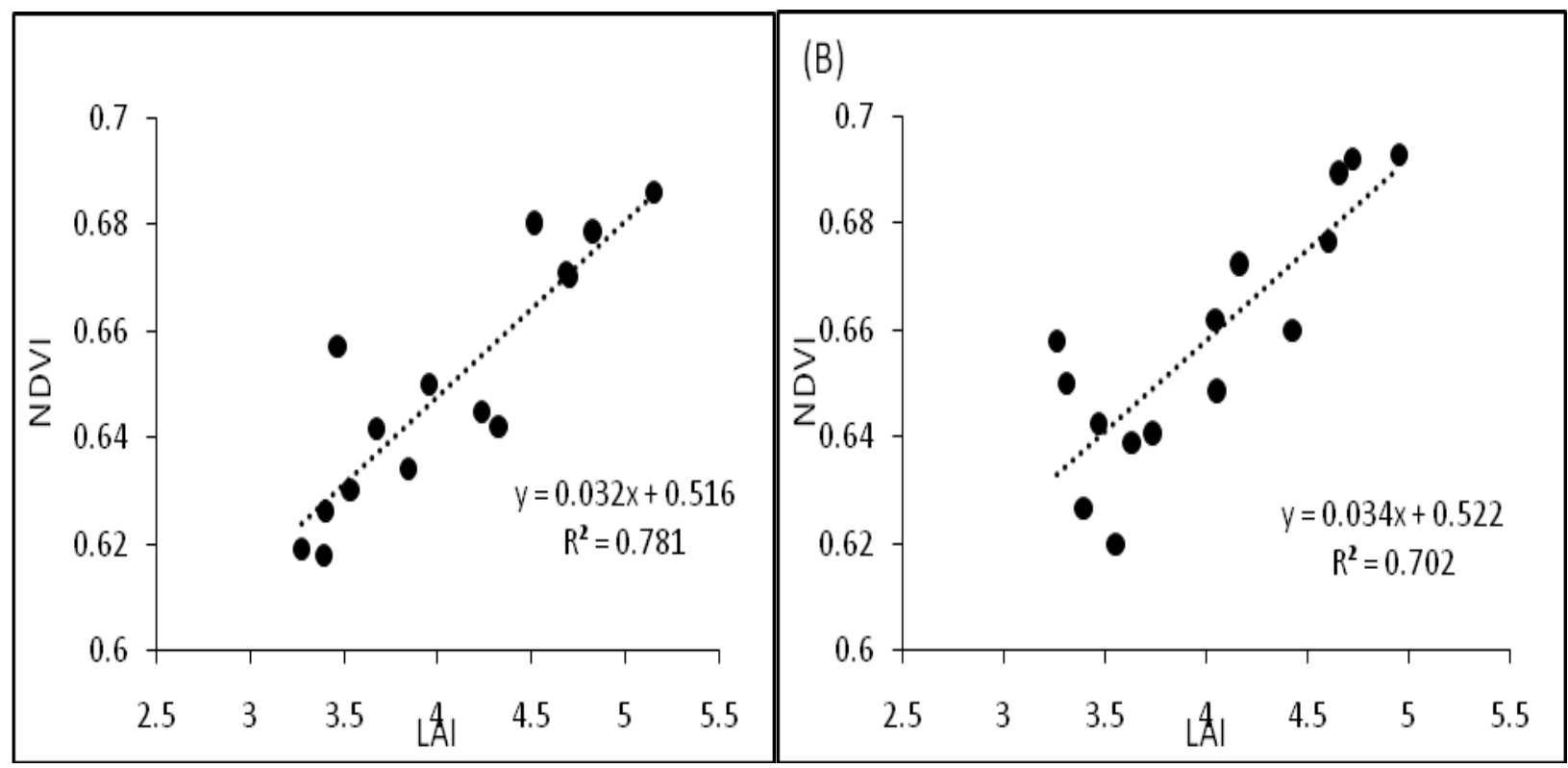

Fig.4 Relationship between NDVI and fIPAR (A) 2014-15 (B) 2015-16 at 78 DAS

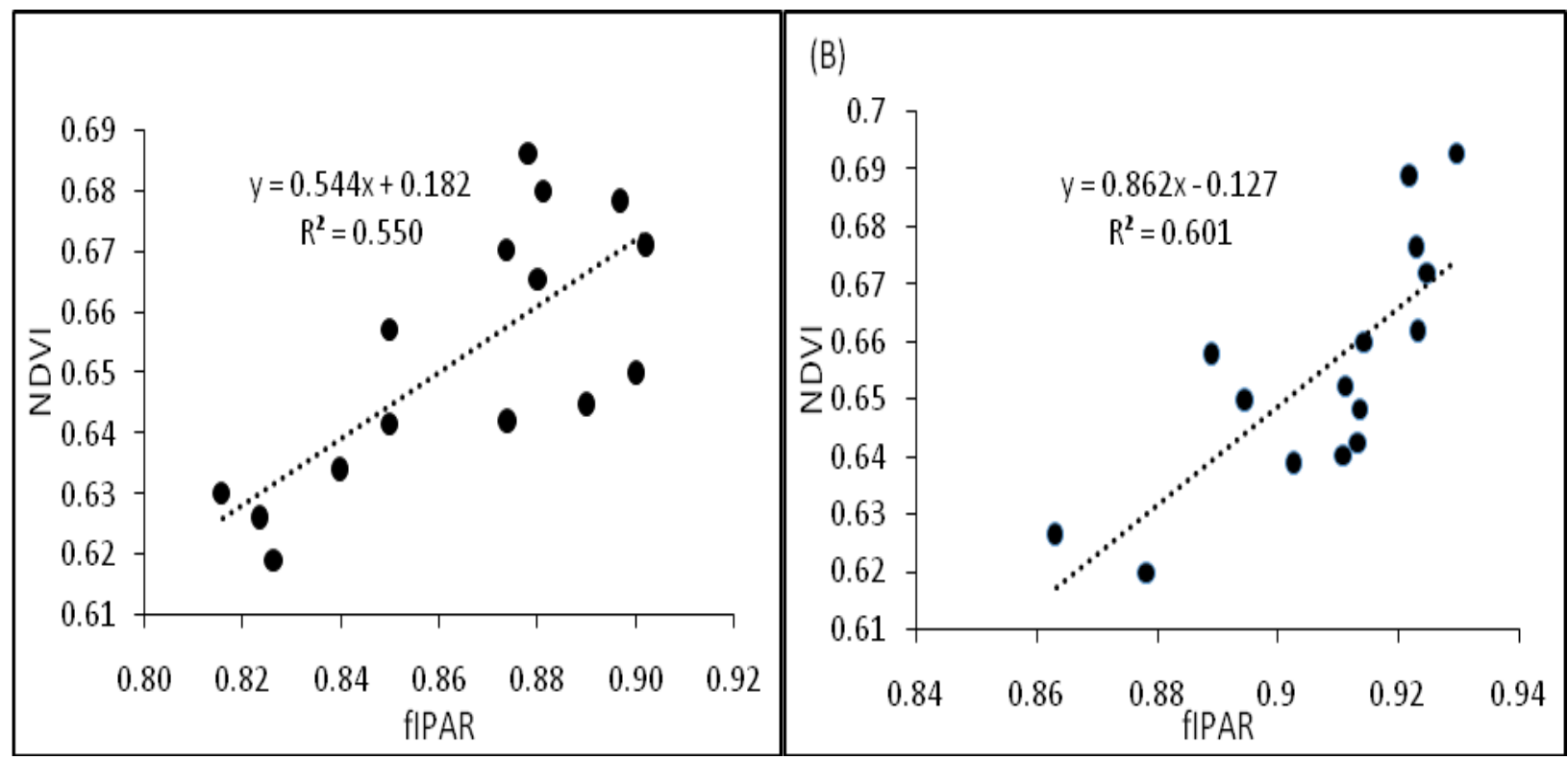


Per cent reduction of spectral radiance in both the year showed that under R5 two reduction deep occurred in two bands (375-446 nm and 593-697 nm), in $\mathrm{R} 4$ reduction deep occurred in one band (593-697 $\mathrm{nm}$ ), in $\mathrm{R} 3$ reduction deep occurred in one band (591-689 nm) and in $\mathrm{R} 2$ reduction deep occurred in (575-765 nm) (Fig.2).

\section{Relationship of NDVI with LAI}

The regression equations between LAI versus NDVI for different treatments during 2014-15 and 2015-16 are presented by Fig.3. The positive correlations were observed for all treatments during both years. It was found that value of coefficient of determination was maximum for linear. In year2014-15, the value of R2for linear was 0.78 while during 2015-16 R2value was 0.70. Hence, this relation was found best suitable for the estimation of LAI from NDVI.

\section{Relation between NDVI and fIPAR}

The regression equations between NDVI and fIPAR for different treatments during 2014-15 and 2015-16 are presented by Fig. 4. The correlation was positive for all treatments during both years. In year 2014-15, the value of R2 for linear was 0.55 while during 201516 R2 value was 0.60 with linear relation. Hence, this relation was found best suitable for the estimation of fIPAR from NDVI.

In conclusion, reduced solar radiation can adversely affects the plant growth and yield of wheat. Spectral radiance or signature of wheat was also influenced by the degree of reduced radiation. More spectral radiance was received by $\mathrm{R} 1$ treatment followed by $\mathrm{R} 2, \mathrm{R} 3$, $\mathrm{R} 4$ and R5 respectively. Spectral radiance of blue band (400-500nm) was more inside the severe nets compared to mild net and open condition. The regression equations between LAI -NDVI and fIPAR-NDVI were developed for different treatments during 2014-15 and 2015-16. The positive correlations were observed for all treatments during both years.

\section{References}

Bell, G.E., Danneberger, T.K. and McMahon, M.J. 2000. Spectral irradiance available for turf grass growth in sun and shade. Crop Sci., 40:189-195.

Greenwald, R., Bergin, M.H., Xu, J., Cohan, D., Hoogenboom, $\mathrm{G}$ and Chameides, W.L. 2006. The influence of aerosols on crop production: a study using the CERES crop model. Agricultural Systems, 89: 390-413.

Kumari, P.B. and Goswami, B.N. 2007. Seminal role of clouds on solar dimming over the Indian monsoon region. Geophysical Res. Lett., 37(6).

Li, H., Jiang, D., Wollenweber, B., Dai, T. and Cao, W. 2010. Effects of shading on morphology, physiology and grain yield of winter wheat. European J. Agron., 33: 267-275.

Liepert, B.G. 2002. Observed reductions of surface solar radiation at sites in the United States and worldwide from 1961 to 1990. Geophysical Res. Lett., 29(10): 1421.

Liu, S., Chen, M. and Zhuang, Q. 2014. Aerosol effects on global land surface energy fluxes during 2003-2010. Geophysical Res. Lett., 41(22): 7875-7881.

Ramanathan, V., Chung, C., Kim, D., Bettge, T., Buja, L., Kiehl, J.T. and Wild, M. 2005. Atmospheric brown clouds: Impacts on South Asian climate and hydrological cycle. Proceedings of the National Academy of Sciences of the United States of America, 102(15): 53265333.

Rouse, J.W., Haas, R.H., Schell, J.A. and Deering, D.W. 1974. Monitoring vegetation systems in the Great Plains with ERTS. NASA Special Publication, 351(1): 307-317. 
Soni, V.K., Pandithurai, G. and Pai, D.S. 2012. Evaluation of long- term changes of solar radiation in India. Int. J. Climatol., 32(4): 540-551.

Urban, O., Klem, K., Ac, A., Havrankova, K., Holisova, P., Navratil, M. and Grace, J. 2012. Impact of clear and cloudy sky conditions on the vertical distribution of photosynthetic $\mathrm{CO} 2$ uptake within a spruce canopy. Functional Ecol., 26: 4655.

Wild, M., Gilgen, H., Roesch, A., Ohmura, A., Long, C.N., Dutton, E.G. and Tsvetkov, A. 2005. From dimming to brightening: Decadal changes in solar radiation at Earth's surface. Sci., 308(5723): 847-850.

\section{How to cite this article:}

Brijesh Yadav, Anil Kumar Verma, Sushil Kumar Kharia, Avinash Goyal, Ravi Kumar Meena and Chiranjeev Kumawat. 2017. Relationship between NDVI, LAI, fIPAR in wheat Under Reduced Solar Radiation in Delhi NCR Region. Int.J.Curr.Microbiol.App.Sci. 6(5): 2671-2676. doi: https://doi.org/10.20546/ijcmas.2017.605.299 